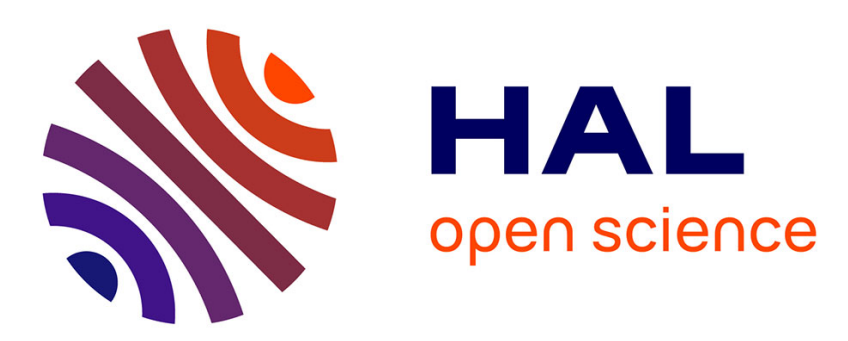

\title{
Expression pattern of the homeotic gene Bapx1 during early chick gastrointestinal tract development
}

Sandrine Faure, Maxime Georges, Jennifer Mckey, Sébastien Sagnol, Pascal de Santa Barbara

\section{- To cite this version:}

Sandrine Faure, Maxime Georges, Jennifer Mckey, Sébastien Sagnol, Pascal de Santa Barbara. Expression pattern of the homeotic gene Bapx1 during early chick gastrointestinal tract development. Gene Expression Patterns, 2013, 10.1016/j.gep.2013.05.005 . hal-02543674

\section{HAL Id: hal-02543674 \\ https://hal.umontpellier.fr/hal-02543674}

Submitted on 15 Apr 2020

HAL is a multi-disciplinary open access archive for the deposit and dissemination of scientific research documents, whether they are published or not. The documents may come from teaching and research institutions in France or abroad, or from public or private research centers.
L'archive ouverte pluridisciplinaire HAL, est destinée au dépôt et à la diffusion de documents scientifiques de niveau recherche, publiés ou non, émanant des établissements d'enseignement et de recherche français ou étrangers, des laboratoires publics ou privés. 


\title{
Expression pattern of the homeotic gene Bapx1 during early chick gastrointestinal tract development
}

\author{
Sandrine Faure, Maxime Georges, Jennifer McKey, Sébastien Sagnol, Pascal de Santa Barbara* \\ INSERM U1046, Université Montpellier 1, Université Montpellier 2, 371 Avenue Doyen Giraud, 34295 Montpellier, France
}

A R T I C L E I N F O

Keywords:

Bapx1

BMP pathway

Gastrointestinal tract

Smooth muscle

Chick development

\begin{abstract}
A B S T R A C T
Regulation of the Bone Morphogenetic Protein (BMP) signaling pathway is essential for the normal development of vertebrate gastrointestinal (GI) tract, but also for the differentiation of the digestive mesenchymal layer into smooth muscles and submucosal layer. Different studies demonstrated that Bapx1 (for bagpipe homeobox homolog 1) negatively regulates the BMP pathway, but its precise expression pattern during the development and the differentiation of the GI tract mesenchyme actually remains to be examined. Here, we present the spatio-temporal expression profile of Bapx1 in the chick GI tract. We show that Bapx1 is first expressed in the undifferentiated mesenchyme of the gizzard and the colon. After the differentiation of the digestive mesenchyme, we found Bapx1 strongly expressed in the gizzard smooth muscle and in the submucosa layer of the colon. This expression pattern provides new insights into the roles of Bapx1 during the regionalization of the GI tract and the differentiation of the digestive mesenchyme of the colon and the stomach.
\end{abstract}

The gastrointestinal (GI) tract is a remarkably complex, three dimensional, specialized and vital organ system derived from a simple tubular structure. The vertebrate GI tract includes the lumenal digestive system of the esophagus, stomach, intestines, and colon (which we will designate as "gut") and the GI tract derivatives - thyroid, lungs, liver, and pancreas (Grapin-Botton, 2005; Roberts, 2000; de Santa Barbara et al., 2002). The gut is composed of the three germ layers - mesoderm (which forms the smooth muscle layer), endoderm (which forms the epithelial lining), and ectoderm (which includes the enteric nervous system). Originally, the gut develops from two meso-endodermal invaginations at the anterior (anterior intestinal portal, AIP) and posterior (caudal intestinal portal, CIP) end of the embryo, which elongate and fuse to form a straight tube. This primitive gut tube is initially patterned into three broad domains along its anterior-posterior (AP) axis: the fore-, mid- and hindgut. As they develop, each region of the gut acquires mesodermal and endodermal morphologies, which can be easily discerned by gross and microscopic examination. These tissues differentiate in a regionally specific pattern of differentiation along the AP axis, designating the pharynx, esophagus, and stomach (the foregut), small intestines (the midgut), and large intestines (hindgut). In addition to this AP axis differentiation, the digestive mesenchyme differentiates along the radial axis and

\footnotetext{
* Corresponding author. Address: INSERM U1046, Physiology and Experimental Medecine of Heart and Muscles, 371 Avenue Doyen Giraud, 34295 Montpellier, France. Tel.: +33467 4152 34; fax: +33467415231.

E-mail address: Pascal.de-Santa-Barbara@inserm.fr (P. de Santa Barbara).
}

gives rise to the submucosa and smooth muscle layers (Faure and de Santa Barbara, 2011).

Candidate factors for GI mesoderm regionalization include nuclear transcription factors (as Hox and Nkx factors) and secreted factors (such as Hedgehog ligands) (de Santa Barbara and Roberts, 2002; Smith et al., 2000; Ramalho-Santos et al., 2000). Bone morphogenetic proteins (BMP) are secreted signaling molecules that belong to the Transforming Growth Factor $\beta$ (TGF $\beta$ ) superfamily. BMP ligands were initially identified as key regulators of bone formation (Urist et al., 1979), but subsequent analyses have demonstrated that these ligands regulate a spectrum of developmental processes throughout embryogenesis and organogenesis (reviewed in Hogan (1996); de Santa Barbara et al., 2003). Early during GI development, Bmp4 is expressed in the mesenchyme of the entire gut exclusive of the gizzard (Roberts et al., 1998). When misexpressed in the gizzard, Bmp4 induces an upregulation of the pyloric sphincter marker $N k x 2.5$ in the posterior gizzard mesoderm (Smith and Tabin, 1999; Smith et al., 2000). These experiments indicate that a low level of BMP signaling activity is a prerequisite for the correct regionalization of the stomach. Out of the candidate genes for regulating BMP signaling during GI tract development in the chick embryo is the homeotic gene Bapx1 (also named Nkx3.2). Bapx1 expression has been reported for the vertebrate stomach (Nielsen et al., 2001; Akazawa et al., 2000; Verzi et al., 2009). In chick, Bapx1 is expressed early during development in the gizzard mesenchyme but not in the proventriculus (Nielsen et al., 2001). Ectopic expression of Bapx1 in the proventriculus results in a gizzard-like morphology and inhibits normal proventricular 
expression of Bmp4, strongly suggesting a role for Bapx1 in the regionalization of the chick stomach through the control of Bmp4 expression (Nielsen et al., 2001; de Santa Barbara et al., 2005). In addition, it has been shown that when Bmp4 is misexpressed in the gizzard mesoderm, smooth muscle differentiation is impaired (Smith et al., 2000; de Santa Barbara et al., 2005). A regulated level of BMP signaling activity is then a prerequisite for normal development and differentiation of the gizzard mesenchyme (de Santa Barbara et al., 2005; Notarnicola et al., 2012). Although it has been shown that the ectopic expression of Bapx1 causes a marked muscular hypertrophy (Nielsen et al., 2001; de Santa Barbara et al., 2005), its expression profile during the differentiation of the mesenchymal layer into smooth muscle and submucosa remains to be examined.

The goal of this study was to analyze the endogenous expression pattern of Bapx 1 during the process of smooth muscle differentiation, from $\mathrm{E} 4$ to $\mathrm{E} 9$, in the developing chick GI tract.

\section{Results}

\subsection{Bapx1 expression in E4 chick GI tract}

In order to investigate the expression pattern of Bapx 1 during the development of the digestive tract, we first performed whole mount in situ hybridization analyses on 4-day-old dissected guts (E4 or stages 23-24) and observed that Bapx1 is expressed at high level in the stomach and the colon (Fig. 1A, C and E). Moreover, in situ hybridization analyses performed on paraffin sections revealed that Bapx1 expression is localized in the whole mesenchyme of the stomach and the colon (Fig. 1D and F). At these stages, the primitive gut presents no morphological differences along the anteroposterior axis. The whole digestive mesenchyme is undifferentiated as demonstrated by the absence of $\operatorname{Sm} 22$ expression, a specific differentiated smooth muscle cell marker (Fig. 1B). All together, these data demonstrate that Bapx1 is expressed at early stages of GI development. Its expression is localized in the mesenchyme of the stomach and the colon before their differentiation into smooth muscle.

\subsection{Bapx1 expression in $E 7$ chick GI tract}

At E7 (Stage 31), the chick GI tract is regionalized into the stomach, the small intestine and the colon. Intestine and colon are separated by the bilateral caeca. The stomach is composed of two structures: the gizzard and the proventriculus, respectively the muscular and glandular stomach (Fig. 2A). At this stage, the mesenchyme of the GI tract is differentiated in smooth muscle as demonstrated by Sm22 staining uniformly localized into the GI musculature with the exception of the caeca and the two intermuscular tendons present in the stomach (Le Guen et al., 2009) (Fig. 2B). Whole-mount in situ hybridization analyses performed at this stage revealed a high level of Bapx1 expression in the gizzard (Fig. 2C and D). A strong expression of Bapx1 was also detected in the pylorus, a structure that allows the connection of the stomach to the duodenum (Fig. 2C). Immunostaining on paraffin sections indicated that at this stage, the mesenchyme of the stomach is differentiated along the radial axis into submucosa (negative for the specific alpha Smooth Muscle Actin marker ( $\alpha$ SMA)) and smooth muscle (positive for aSMA) layers. The enteric nervous system precursors (positive for HNK-1), organized in myenteric plexi, are localized in the outer part of the smooth muscle domain (Fig. 2E and H). Comparison of Bapx1 in situ staining to $\alpha \mathrm{SMA} / \mathrm{HNK}-1$ immunostainings performed on adjacent longitudinal sections indicated that Bapx1 is highly expressed in smooth muscle cells in the gizzard (Fig. 2F; compare Fig. 2G and
H). In addition, a faint expression of Bapx1 was also detected in the aSMA-negative submucosa layer. In the smooth muscle domain, Bapx1 expression was not detected in the plexi (Fig. 2G). At E7, the colon smooth muscle is well differentiated, as demonstrated by the expression of aSMA on paraffin sections (Fig. 2I). We found that Bapx1 is highly expressed in the colon (Fig. 2C, D and $\mathrm{J}$ ). Interestingly, its expression is lower in the posterior part of the colon and even almost no detectable in the rectum (Fig. 2J). Analyses of Bapx1 staining on paraffin sections revealed that Bapx1 is localized in the submucosa layer with a higher level in cells of the submucosa layer bordering with the epithelium and the smooth muscle domain (compare Fig. 2I-K). These observations are confirmed by simultaneous in situ hybridization with Bapx1 coupled to immunofluorescence with aSMA analyses on the same colonic section (Fig. 2L).

\subsection{Bapx1 expression in E9 chick GI tract}

Whole-mount in situ hybridization analyses performed at E9 (Stage 35) revealed Bapx1 expression in the gizzard, the pylorus and the colon. No expression was detectable in the rectum (Fig. 3A and B). At this stage, we observed a new area of expression in the whole small intestine (see arrowhead Fig. 3A). As previously observed at earlier stages (see Fig. 2), the expression of Bapx1 in the gizzard is high and localized in the smooth muscle layers (compare Fig. 3 C and D). A very faint staining was also detected in the submucosa layer (see magnified views in Fig. 3E and F). More posteriorly, we found that all smooth muscle layers (longitudinal, circular and oblique) are positive for Bapx1 (compare Fig. 3G and $\mathrm{H}$ ). The expression of Bapx1 was also observed in the colon (Fig. 3I). At this stage, the colon harbors two $\alpha$ SMA positive smooth muscle cell domains that constitute, from outer to inner, the longitudinal and circular smooth muscle layers. The enteric neural crest precursors, positive for HNK-1, are organized into myenteric and submucosal plexi (shown respectively by white and red arrowheads in Fig. 3J). Comparison of Bapx1 in situ staining to $\alpha \mathrm{SMA} / \mathrm{HNK}-1$ immunostainings performed on adjacent longitudinal sections revealed that Bapx1 is expressed both in the submucosa and the smooth muscle layers, with a stronger expression in cells located at the junction between these two domains (compare Fig. 3J and $\mathrm{K})$. Interestingly, we observed that the width of Bapx1 expression domain in the smooth muscle decreases along the AP axis of the colon (Fig. 3I). Only a stripe of Bapx1 expression was found in a group of cells bordering the submucosa layer at the transition between colon and rectum (compare Fig. 3L and $\mathrm{M}$ ) consistent with the absence of Bapx1 expression observed in the rectum (arrows in Fig. 3B). In the small intestine, the expression of Bapx1 is mainly localized in the submucosa layer and in the outer part of the undifferentiated intestinal mesenchyme (see respectively black and white arrows, Fig. 3N and $\mathrm{O}$ ). These observations are confirmed by simultaneous in situ hybridization with Bapx1 coupled to immunofluorescence with aSMA analyses on the same section (Fig. 3P). Interestingly, no expression was detectable in the intestinal smooth muscle (compare Fig. 3N-P).

\section{Discussion}

It was previously shown that a low level of BMP signaling activity is a prerequisite for normal development and differentiation of the digestive mesenchyme (Roberts et al., 1998; Smith et al., 2000; de Santa Barbara et al., 2005; Notarnicola et al., 2012). A candidate gene for regulating BMP signaling during GI tract development in the chick embryo is the homeotic gene Bapx1 (or Nkx3.2) (Nielsen et al., 2001). Both gain-and loss-of Bapx1 functions have suggested a role for this gene in regulating the expression and patterning of 

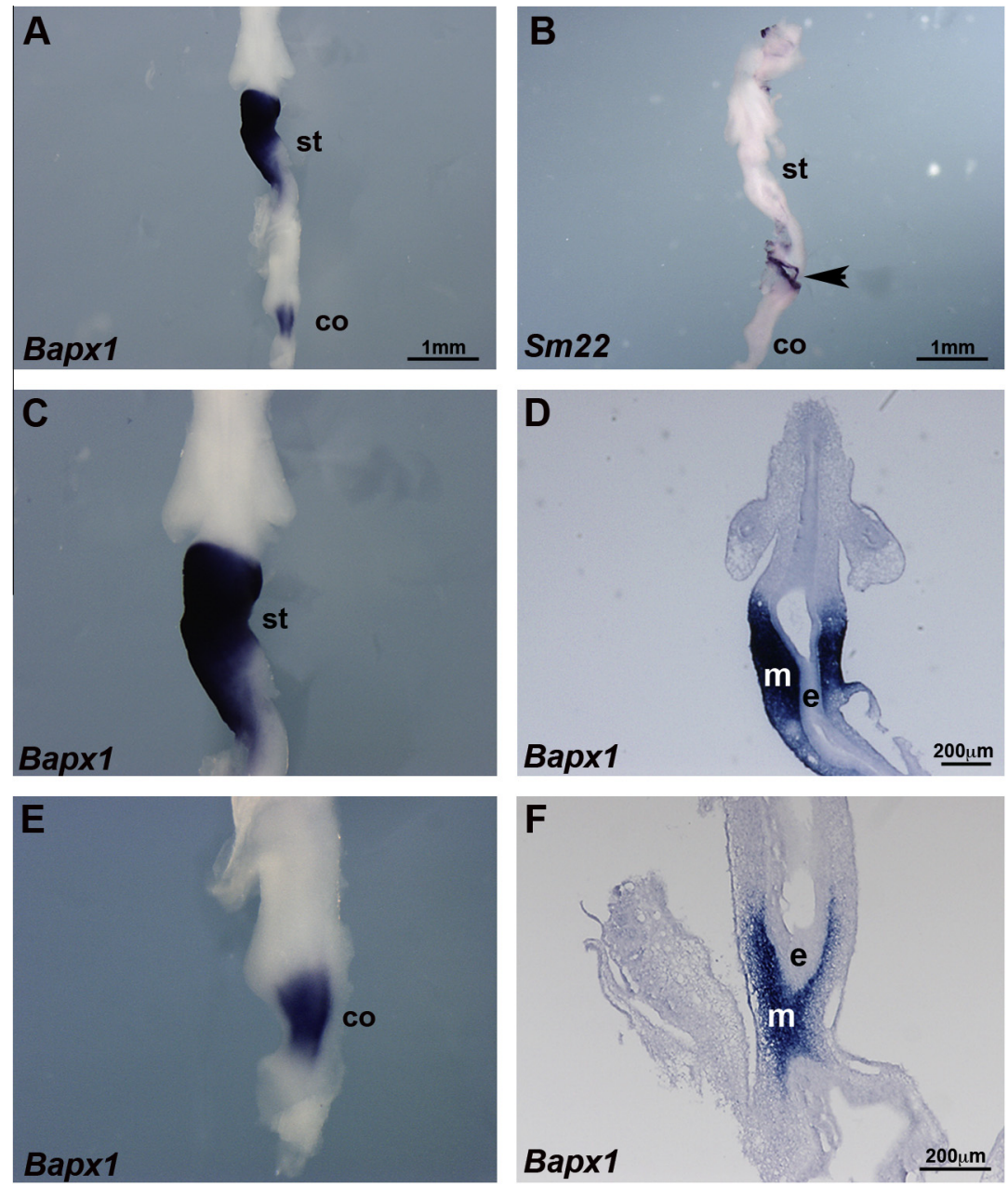

Fig. 1. Bapx1 expression in E4 chick GI tract. (A) Whole mount in situ hybridization analysis of Bapx1. Ventral view. Bapx1 is detected in the stomach and the colon. (B) Whole mount in situ hybridization analysis of Sm22 expression. Ventral view. Sm22 is not expressed into the GI musculature. Note: Sm22 expression in the umbilic vessel that is present around the small intestine (arrowhead). (C and E) Magnified views of the stomach (C) and the colon (E) of the GI tract shown in A. (D and F) Bapx1 in situ hybridization analysis directly performed on longitudinal paraffin sections of the stomach (D) and colon (F) showing a mesenchymal expression of Bapx1 in the stomach and the colon. Abbreviations: e, endoderm; co, colon; m, mesenchyme; st, stomach.

Bmp4 in the chick stomach (Nielsen et al., 2001). In this study, we report the endogenous expression pattern of Bapx1 during the chick GI tract development and digestive smooth muscle differentiation.

We found that Bapx1 is expressed in the mesenchyme of the gizzard during the early stages of GI development and that its expression is maintained in the mesenchyme during its differentiation into smooth muscle. Later on, Bapx1 expression is localized in all the smooth muscle layers (longitudinal, circular and oblique) of the gizzard. The expression of Bapx1 in the smooth muscle of the stomach is maintained during development as we observed its expression at E18 (data not shown), when the digestive musculature is functional (Notarnicola et al., 2012).

In addition, we found an unexpected expression of Bapx 1 in the pylorus, a conserved structure that connects the stomach to the duodenum. The development of the pyloric structure is controlled by the activity of the BMP signaling pathway (Smith and Tabin, 1999; Smith et al., 2000; Moniot et al., 2004). It has been reported that a sustained expression of Bapx1 in the pylorus induces a hypertrophic pyloric sphincter, highly related to the Infantile Hypertrophic Syndrome observed in humans (Roberts et al., 1998; de Santa Barbara et al., 2002, 2005; Smith and Tabin, 1999; Moniot et al., 2004). Taken together, these results suggest that the endogenous expression of Bapx1 has to be tightly regulated during the development of this structure.

In this study, we also report an early expression of Bapx 1 in the colonic mesenchyme. This observation is unexpected, as it has been shown that Bmp4 is strongly expressed in the colon at this early stage of GI tract development (Roberts et al., 1998; Smith et al., 2000; our unpublished results). Later during the differentiation of the colonic mesenchyme, Bapx1 is highly expressed in the submucosa layer, a domain composed of loose cells that express numerous extracellular matrix proteins such as laminin and fibronectin (Simon-Assmann et al., 1994). To our knowledge, Bapx1 is the first transcription factor described so far to be expressed in the submucosa layer of the colon. At later stage (E9), Bapx1 is expressed in the smooth muscle and the submucosa layer of the colon. Interestingly, we observed a gradient of Bapx1 expression along the AP axis in the colonic smooth muscle. Posteriorly, only a stripe of Bapx1 expression was found in the smooth muscle, in a group of cells bordering the submucosa layer. The expression of Bapx1 in the inner-most part of the muscle layer in the colon was also observed at E18 (data not shown).

All together, our study provides new perspectives concerning the roles of Bapx1 during the development and differentiation of digestive musculature. 
A
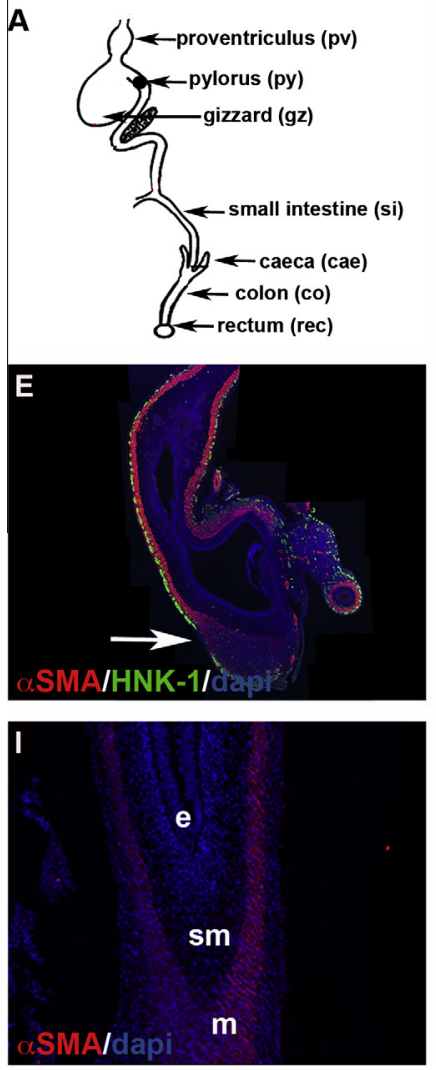
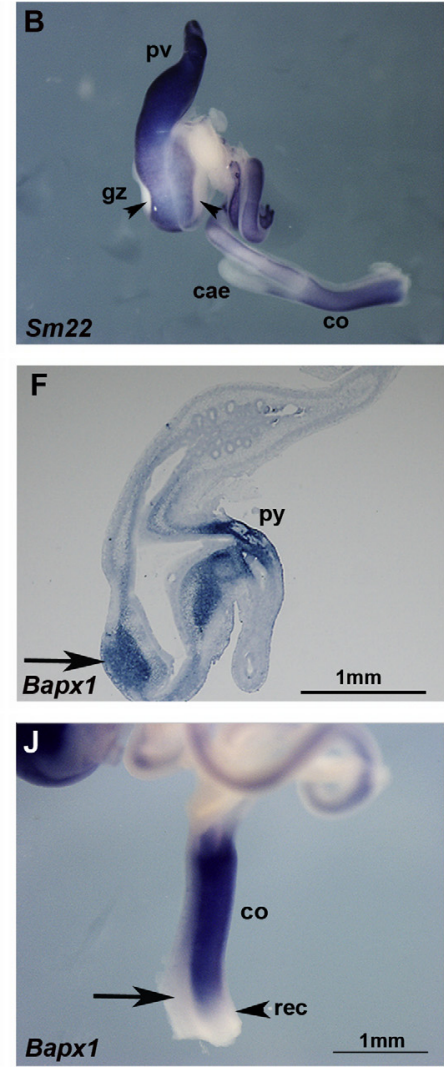
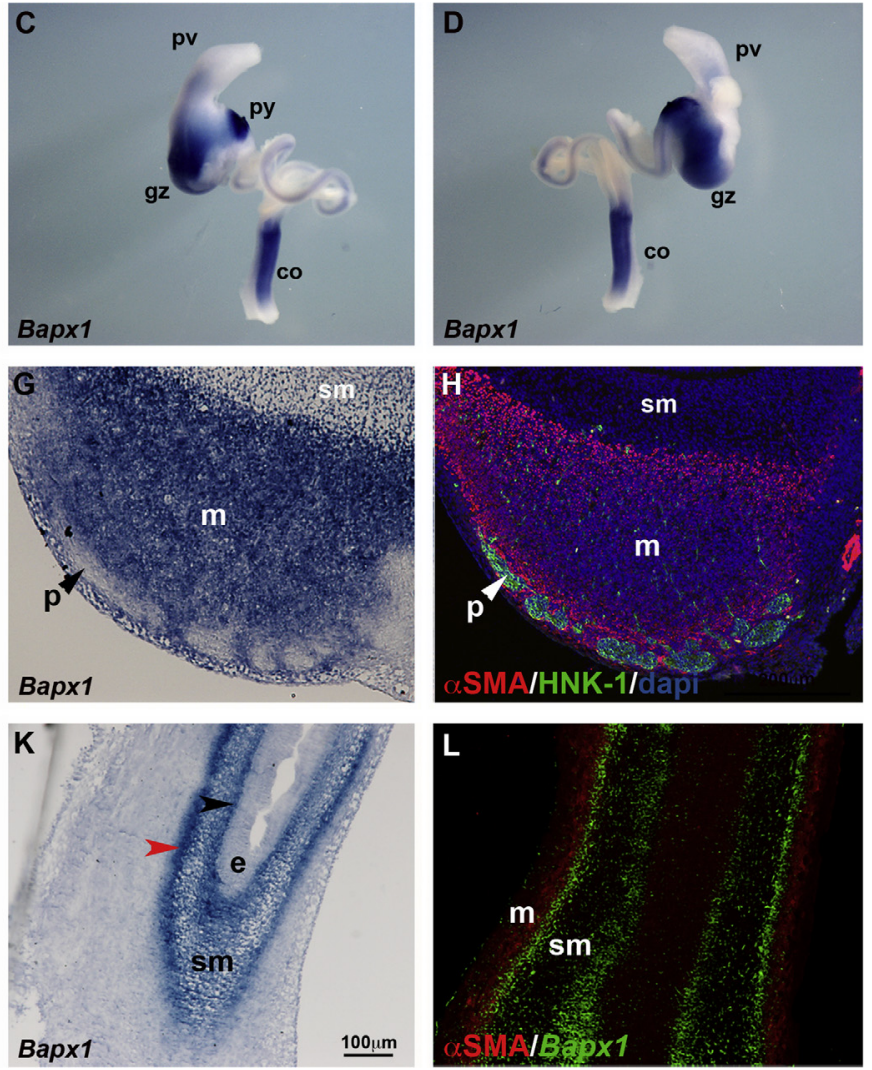

Fig. 2. Bapx1 expression in E7 chick GI tract. (A) Scheme illustrating the regionalized GI tract. (B) Whole mount in situ hybridization analysis of Sm22. Ventral view. Sm22 is expressed in the whole GI tract with the exception of the two intermuscular tendons (arrowheads) and the caecum. (C and D) Whole mount in situ hybridization analysis of Bapx1. Ventral (C) and dorsal (D) views. Bapx1 is highly expressed in the gizzard and the colon. (E) Immunofluorescence analysis performed on longitudinal paraffin sections using anti-aSMA and anti-HNK-1 antibodies showing respectively digestive smooth muscle cells (red) and enteric nervous cell precursors (green) organized in myenteric plexi. (F) In situ hybridization analysis of Bapx1 expression directly performed on adjacent longitudinal sections. In the stomach, Bapx1 is expressed in the smooth muscle cells in the gizzard and the pylorus. $(G)$ Magnified view of the stomach shown in F (black arrow). Bapx1 is expressed in the smooth muscle domain. (H) Magnified view of the stomach shown in $\mathrm{E}$ (white arrow). White arrowhead indicates myenteric plexi. (I) Immunofluorescence analyses performed on longitudinal paraffin sections using antiaSMA antibody. (J) Magnified view of the colon shown in C and D. (K) In situ hybridization analysis of Bapx1 expression directly performed on sections. In the colon, Bapx1 is mainly expressed in the submucosa layer. Note the high level of Bapx1 expression in a group of cell bordering both the epithelium (black arrowhead) and the smooth muscle domain (red arrowhead). (L) Longitudinal paraffin section processed for both in situ hybridization (using Bapx1 riboprobe) and immunofluorescence (using anti- $\alpha$ SMA antibody) analyses. Bapx 1 is expressed in the submucosa layer adjacent to the smooth muscle domain that is positive for $\alpha \mathrm{SMA}$. Abbreviations: cae, caecum; co, colon; e, epithelium; gz, gizzard; m, smooth muscle layer; pv, proventriculus; py, pylorus; rect, rectum; sm, submucosa; st, stomach.

\section{Experimental procedures}

\subsection{Chick embryos}

Timed fertilized white Leghorn eggs (Haas Farm, France) were incubated at $38^{\circ} \mathrm{C}$ in a humidified incubator (Coudelou, France) until used experimentally. Embryos were staged according to Hamburger and Hamilton (1951) by embryonic day (E) for gastrointestinal tract analysis. Dissected gastrointestinal tissues were fixed in $4 \%$ paraformaldehyde for $1 \mathrm{~h}$ at room temperature, washed in PBS, gradually dehydrated in Methanol in order to store the samples at $-20^{\circ} \mathrm{C}$ before processing for whole-mount in situ hybridization as described below (Faure et al., 2002).

\subsection{Whole-Mount in Situ hybridization}

Whole-mount in situ hybridization analyses were carried out as described by Moniot et al. (2004) using antisens Bapx1 (Nielsen et al., 2001) and Sm22 riboprobes. Chick Sm22 cDNA was isolated, sequenced and used to prepare riboprobes for in situ hybridization using specific primer pair of chick Sm22 (Gene Bank ID: NM_205494.1; forward: 5'-TGA GCA GGG ATG TCC AGT -3', reverse: 5'- AGC CAA TGA TGT TCT TGC C-3' generated a 501 bp fragment cloned into the pGEMT-Easy plasmid (Invitrogen). Tissues were gradually rehydrated in PBS, washed in PBT (PBS, $0.1 \%$ Tween) and incubated for $1 \mathrm{~h}$ in $6 \%$ hydrogen peroxide (Sigma, France). Samples were next permeabilized by treatment with proteinase $\mathrm{K}(10 \mu \mathrm{g} / \mathrm{ml})$ for $10 \mathrm{~min}$, washed with glycine in PBT and fixed in $4 \%$ paraformaldehyde/ $0.2 \%$ gluteraldehyde in PBT for 20 min. Tissues were then hybridized with antisens Bapx 1 or Sm22 digoxigenin-labelled (Roche) riboprobes overnight at $70^{\circ} \mathrm{C}$. After post-hybridization washes at $70^{\circ} \mathrm{C}$, tissues were incubated in $10 \%$ sheep serum for $2.5 \mathrm{~h}$ at room temperature and finally mixed with preabsorded anti-digoxigenin coupled with alkaline phosphatase antibody (Roche) overnight at $4{ }^{\circ} \mathrm{C}$. The complexes were detected with BM purple solution (Roche).

\subsection{Immunohistochemistry and in situ hybridization on paraffin sections}

For sectioning, tissues were first gradually dehydrated in Ethanol, incubated in HistoClear solution (VWR, France) and finally embedded in Paraffin. Samples were sectioned at $10-\mu \mathrm{m}$ using a microtome and collected on Polysine coated-slides (Thermo Fisher). In situ hybridization experiments on paraffin sections were carried out as previously described (Moniot et al., 2004) using antisens Bapx1 riboprobes (Nielsen et al., 2001). Immunofluorescence 

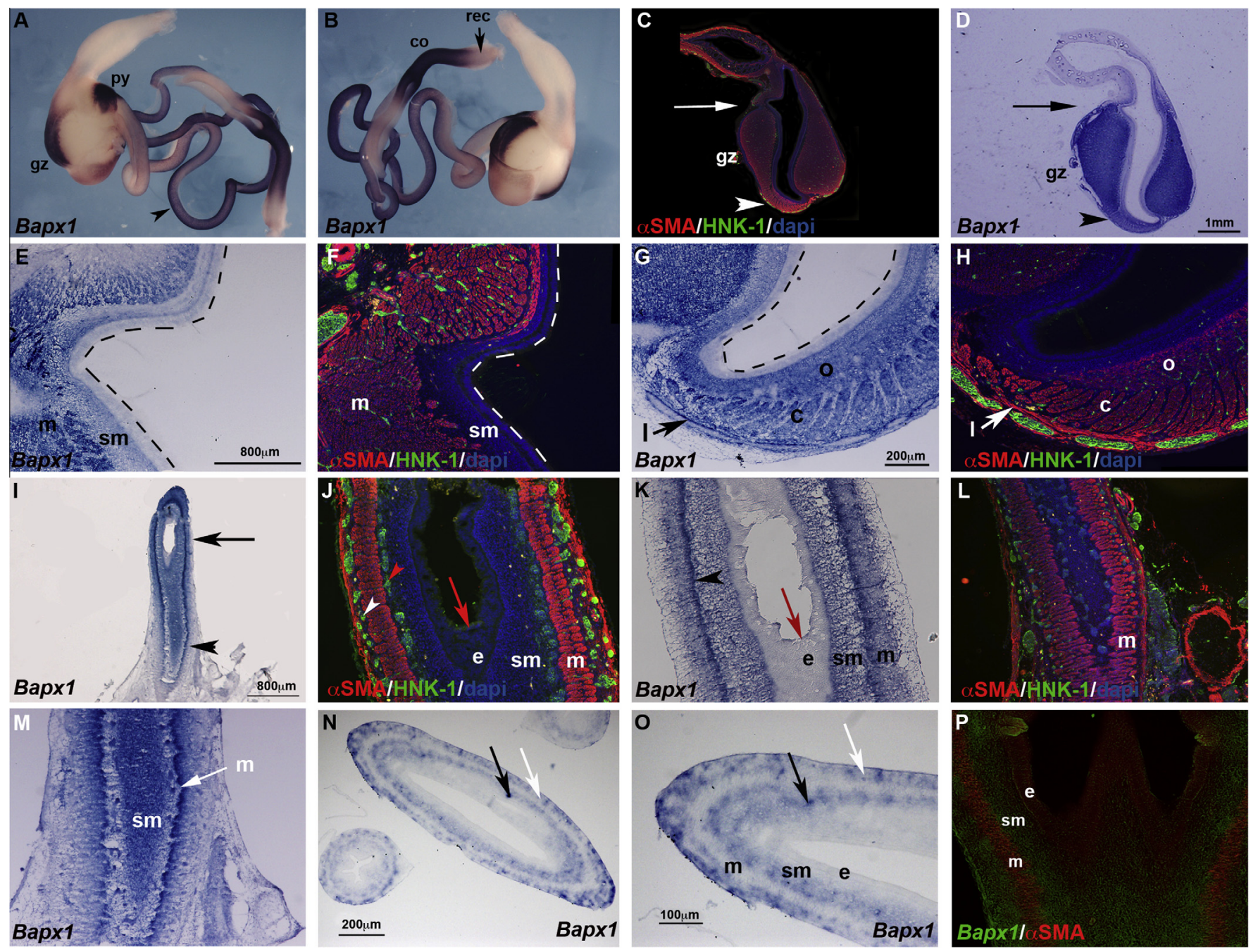

Fig. 3. Bapx1 expression in E9 chick GI tract. (A and B) Whole mount in situ hybridization analysis of Bapx1. Ventral (A) and dorsal (B) views. Bapx1 expression is maintained in the gizzard and colon. At this stage, its expression is also detected in the small intestine (arrowhead). Note that its expression is low in the caecum and undetectable in the rectum (arrow). (C) Immunofluorescence analysis performed on longitudinal paraffin sections using anti- $\alpha$ SMA and anti-HNK-1 antibodies showing respectively digestive smooth muscle cells (red) and enteric nervous cell precursors organized in myenteric plexi (green). (D) In situ hybridization analysis of Bapx1 expression directly performed on adjacent longitudinal sections. In the gizzard, Bapx1 is highly expressed in the smooth muscle domain. (E) Magnified view of the stomach shown in D (black arrow) showing the expression of Bapx1 in the smooth muscle cells. A faint signal was also detected in the submucosa layer. (F) Magnified view of the stomach shown in C (white arrow). (G) Magnified view of the stomach shown in D (black arrowhead) showing the expression of Bapx1 in the smooth muscle cells in the longitudinal, circular and oblique layers. $(\mathrm{H})$ Magnified view of the stomach shown in $\mathrm{C}$ at the level of the white arrowhead. (I) In situ hybridization analysis of Bapx1 expression directly performed on longitudinal sections. In the colon, Bapx1 is highly expressed in the mesenchymal derivate layer. (J) Immunofluorescence analyses on longitudinal paraffin sections using antiaSMA and anti-HNK-1 antibodies showing respectively digestive smooth muscle cells (red) and enteric nervous cell precursors (green) organized in myenteric and submucosal plexi (shown respectively by white and red arrowheads). Red arrow indicates the epithelium layer. (K) Magnified view of the colon shown in I (black arrow). Note the high level of Bapx1 expression at the junction between the submucosa and the smooth muscle layers (black arrowhead). Red arrow indicates the epithelium layer. (L) Immunofluorescence analyses on longitudinal paraffin sections of the colon using anti- $\alpha$ SMA and anti-HNK-1 antibodies. (M) Magnified view of the colon shown in I focusing on the transition between the colon and the rectum (white arrow indicates smooth muscle). (N) In situ hybridization analysis of Bapx1 expression on paraffin sections. In the intestine, Bapx1 is highly expressed in the mesenchymal derivate layer (black and white arrows). (O) Magnified view of the intestine shown in $\mathrm{N}$ showing the expression of Bapx1 in the submucosa layer (black arrow) and in the outer part of the undifferentiated intestinal mesenchyme (white arrow). (P) Paraffin section processed for both in situ hybridization (using Bapx1 riboprobe) and immunofluorescence (using anti- $\alpha$ SMA antibody) analyses. In the small intestine, Bapx1 is expressed in the undifferentiated intestinal mesenchyme (submucosa layer and outer part of the intestinal mesenchyme). Abbreviations: c, circular layer; cae, caecum; co, colon; e, epithelium; gz, gizzard; l, longitudinal layer; m, smooth muscle layer; o, oblique layer; pv, proventriculus; py, pylorus; sm, submucosa layer.

studies were performed on paraffin sections using polyclonal antibodies against aSMA (Sigma-Aldrich) and HNK-1 (NeoMarker). Nuclei were labelled with Hoescht (Invitrogene).

\subsection{Photography}

Images of whole-mount GI tract staining were acquired using a Nikon-AZ100. Images of sections were acquired using a Nikon AZ100 microscope.

\section{Acknowledgements}

We thank the members of INSERM U1046 for constant support. This work was supported by grants from Association Française contre les Myopathies-Trampoline (No. 15681) to S.F. and Chercheur d'Avenir (Region Languedoc-Roussillon) to P.d.S.B. J.M. was supported by the Ministère de l'Education et de la Recherche and S. S. by UM1 Post-doc fellowship. 


\section{Appendix A. Supplementary data}

Supplementary data associated with this article can be found, in the online version,

\section{References}

Akazawa, H., Komuro, I., Sugitani, Y., Yazaki, Y., Nagai, R., Noda, T., 2000. Targeted disruption of the homeobox transcripition factor Bapx1 results in lethal skeletal dysplasia with asplenia and gastroduodenal malformation. Genes Cells 5, 499513.

de Santa Barbara, P., van den Brink, G.R., Roberts, D.J., 2002. Molecular etiology of gut malformations and diseases. Am. J. Med. Genet. 115, 221-230.

de Santa Barbara, P., Roberts, D.J., 2002. Tail gut endoderm and gut/genitourinary/ tail development: a new tissue-specific role for Hoxa13. Development 129, 551-561.

de Santa Barbara, P., van den Brink, G.R., Roberts, D.J., 2003. Development and differentiation of the intestinal epithelium. Cell. Mol. Life Sci. 60, 1322-1332.

de Santa Barbara, P., Williams, J., Goldstein, A.M., Doyle, A.M., Nielsen, C., Winfield S., Faure, S., Roberts, D.J., 2005. Bone morphogenetic protein signaling pathway plays multiple roles during gastrointestinal tract development. Dev. Dyn. 234 $312-322$.

Faure, S., de Santa Barbara, P., Roberts, D.J., Whitman, M., 2002. Endogenous patterns of BMP signaling during early chick development. Dev. Biol. 244, 4465.

Faure, S., de Santa Barbara, P., 2011. Molecular embryology of the foregut. J. Pediatr. Gastroenterol. Nutr. 52, S2-3.

Grapin-Botton, A., 2005. Antero-posterior patterning of the vertebrate digestive tract: 40 years after Nicole Le Douarin's Ph.D thesis. Int. J. Dev. Biol. 49, 335 347.

Hamburger, V., Hamilton, H.L., 1951. A series of normal stages in the development of the chick embryo. J. Morphol. 88, 49-92.
Hogan, B.L., 1996. Bone morphogenetic proteins: multifunctional regulators of vertebrate development. Genes Dev. 10, 1580-1594.

Le Guen, L., Notarnicola, C. de Santa Barbara, P., 2009. Intermuscular tendons are essential for the development of vertebrate stomach. Development 136, 791 801.

Moniot, B., Biau, S., Faure, S., Nielsen, C.M., Berta, P., Roberts, D.J., de Santa Barbara, P., 2004. SOX9 specifies the pyloric pyloric sphincter epithelium through mesenchymal-epithelial signals. Development 131, 3795-3804.

Notarnicola, C., Rouleau, C., Le Guen, L., Virsolvy, A., Richard, S., Faure, S., de Santa Barbara, P., 2012. The RNA-binding protein RBPMS2 regulates development of gastrointestinal smooth muscle. Gastroenterology 143, 687-697.

Nielsen, C., Murtaugh, L.C., Chyung, J.C., Lassar, A., Roberts, D.J., 2001. Gizzard formation and the role of Bapx1. Dev. Biol. 231, 164-174.

Ramalho-Santos, M., Melton, D.A., McMahon, A.P., 2000. Hedgehog signals regulate multiple aspects of gastrointestinal development. Development 127, 27632772.

Roberts, D.J., Smith, D.M., Goff, D.J., Tabin, C.J., 1998. Epithelial-mesenchymal signaling during the regionalization of the chick gut. Development 125, 27912801.

Roberts, D.J., 2000. Molecular mechanisms of development of the gastrointestinal tract. Dev. Dyn. 219, 109-120.

Simon-Assmann, P., Duclos, B., Orian-Rousseau, V., Arnold, C., Mathelin, C., Engvall, E., Kedinger, M., 1994. Differential expression of laminin isoforms and alpha 6beta 4 integrin subunits in the developing human and mouse intestine. Dev Dyn. 201, 71-85.

Smith, D.M., Tabin, C.J., 1999. BMP signalling specifies the pyloric sphincter. Nature 402, 748-749.

Smith, D.M., Nielsen, C., Tabin, C.J., Roberts, D.J., 2000. Roles of BMP signaling and Nkx2.5 in patterning at the chick midgut-foregut boundary. Development 127 3671-3681.

Urist, M.R., Mikulski, A., Lietze, A., 1979. Solubilized and insolubilized bone morphogenetic protein. Proc. Natl. Acad. Sci. USA 76, 1828-1832.

Verzi, M.P., Stanfel, M.N., Moses, K.A., Kim, B.M., Zhang, Y., Schwartz, R.J., Shivdasani, R.A., Zimmer, W.E., 2009. Role of the homeodomain transcription factor Bapx1 in mouse distal stomach development. Gastroenterology 136, 1701-1710. 